\title{
Immunohistochemical Test
}

National Cancer Institute

\section{Source}

National Cancer Institute. Immunohistochemical Test. NCI Thesaurus. Code C51944.

A diagnostic test in which an antibody is used to link a cellular antigen specifically to a stain that can be seen with a microscope. 